\title{
Influence of Antioxidants in Cases of Dry AMD (Age Related Macular Degeneration) Studied with Multifocal ERG
}

\author{
Dr. Sayalee Lahane, Dr. Preetam Samant, Dr. Deepak Bhatt, Dr. T. P. Lahane \\ Sir J J Hospital Campus, Byculla, Mumbai 400008, Maharashtra, India
}

\begin{abstract}
Purpose: The aim of this study is to explore the role of multifocal ERG in the management of patients with dry AMD and to assess the therapeutic role of oral antioxidants in dry AMD using multifocal ERG. Methods: A prospective, non randomized study was conducted in patients with dry AMD. Patients were treated with antioxidants. Ophthalmoscopic examination with multifocal ERG was performed at baseline and after 3 months of antioxidants. Results: There were 40 consecutive eyes of 20 patients who received antioxidants according to AREDS study for 3 months. We found that 37.5\% patient showed improved visual acuity following 3 months of antioxidant, $40 \%$ maintained the visual acuity same as baseline \& in $22.5 \%$ visual acuity worsened. We observed that there was no significant improvement in the amplitude in mfERG above the baseline post 3 months antioxidant treatment on an average in all the patients. In the group of patients with worsened visual acuity there was a statistically significant decrease in the amplitude in ring 1 , ring 2 \& on an average suggests that multifocal ERG amplitude changes correlate well with visual acuity changes. Conclusions: Multifocal ERG is definitely useful investigative tool to access improvement or deterioration of visual function vis-à-vis visual acuity. And the changes in multifocal ERG correlate well with the changes in the visual function in patients with dry AMD.
\end{abstract}

\section{Introduction}

Aging is a natural process which everyone has to undergo. Age related macular degeneration is the degeneration of central portion of retina (i.e. macula) that results in primary loss of central vision. Age related macular degeneration was first described as clinical entity by Otto Haab in 1885. It is the leading cause of irreversible blindness in persons over 50 years of age.

Role of oxidative damage in pathogenesis of ARMD is confirmed by studies like Age related eye disease study $(\mathrm{AREDS})^{1}$. The pathogenesis of AMD is unclear; older age, genetic markers, and cigarette smoking arethe only risk factors consistently reported. Althoughnew treatments have emerged, they are suitable only for thesmall proportion of people with "wet" AMD. No treatmentsare available for the "dry" form, and there is little to offerfor the primary prevention of AMD in older people. Dietary antioxidants have long been suggested as useful forpreventing the development and progression of AMD. ${ }^{2}$ The retina,with its high oxygen content and constant exposure to lightis particularly susceptible to oxidative damage. ${ }^{3}$ Hence the mainstay of the treatment in dry ARMD is antioxidants. Beneficial effects of the antioxidants in terms of visual acuity and functional macular improvement are yet to be proven.

Multifocal electroretinogram is an investigation which allows topographic mapping of function of retina in central $40-50^{\circ}$. It shows reduction in the foveal amplitude and delay in implicit time in cases of dry ARMD. Several studies have investigated the effects of age on mfERG recordings ${ }^{4,5,6,7,8,9,10,11,12,13,14}$. In general, most studies found reductions in mfERGamplitudes and delays in implicit timeswith increasing ageThis study is conducted to see wheather there is any functional improvement of macula after the treatment with antioxidants with the help of changes in amplitude \& implicit time in multifocal ERG.
Also to see whether multifocal ERG can be used as a tool to monitor the progress or worsening of the age related macular degeneration.

\section{Pathophysiology of Age-Related Macular Degeneration}

Insufficient oxygen and nutrients $\downarrow$

Damages photoreceptor molecules $\downarrow$

With ageing, the ability of RPE cells to digest these molecules decreases

$$
\downarrow
$$

Excessive accumulation of residual bodies (drusen)

RPE membrane and cells degenerate and atrophy sets in and central vision is lost

\section{Treatment}

Although there is not as of yet an approved treatment or cure for dry AMD, antioxidants have long been used.

\section{Why antioxidants?}

Antioxidants have long been hypothesized to limit the damagecaused by oxidative stress in the macula.In response to observational studiessuggesting that antioxidants might retard AMD, and to the hypothesis (a popular one at that time) that ambientlight and resultant oxidation in the retina might be a key factorin the development of AMD, antioxidant vitamins were studied.In the Age-RelatedEye Disease Study ${ }^{1}$, which involved 3640 patients (age range,55 to 80 years) with age-related macular degeneration, the useof a daily antioxidant supplement (PreserVision, Bausch \&Lomb) consisting of vitamin C (500 mg), vitamin E (400 IU), beta carotene $(15 \mathrm{mg})$, zinc oxide $(80 \mathrm{mg})$, and cupric oxide( $2 \mathrm{mg})$, as compared with placebo, reduced the rate of 


\section{International Journal of Science and Research (IJSR) \\ ISSN (Online): 2319-7064}

Index Copernicus Value (2015): 78.96 | Impact Factor (2015): 6.391

progressionfrom intermediate to advanced age-related macular degenerationby $25 \%$ over a period of 5 years and resulted in a $19 \%$ reductionin the risk of moderate visual loss. ${ }^{15}$

\section{Materials \& methods}

Type of study: Non randomised prospective study Criteria:

Inclusion criteria:

1) Retinal pigment epithelial defects

2) Few small drusen

3) Intermediate drusen

4) Large drusen

5) Geographic atrophy

Exclusion criteria:

1) Dense cataract

2) Glaucoma

3) Wet ARMD

4) Any other retinal pathology e.g. diabetic retinopathy, hypertensive retinopathy, CRVO, BRVO etc.

5) Any previous laser done

Study plan:

Sample size: 40 eyes of 20 patients

Duration of study: one and half year

Study design:

ARMD was diagnosed by fundus examination post pupil dilatation.

Patients baseline multifocal ERG was done which is taken as control for comparison with post antioxidant multifocal ERG. Patients were given antioxidants according to AREDS regime for 3 months i.e. $500 \mathrm{mg}$ vit $\mathrm{C}, 400 \mathrm{IU}$ vit $\mathrm{E}, 15 \mathrm{mg}$ Beta carotene ,80 mg Zinc oxide, $2 \mathrm{mg}$ cupric oxide

After 3 months of antioxidants multifocal ERG was repeated again. These 2 multifocal ERGS were compared for changes in amplitude $\&$ implicit time.

Case no 5 Fundus photo showing drusen at macula

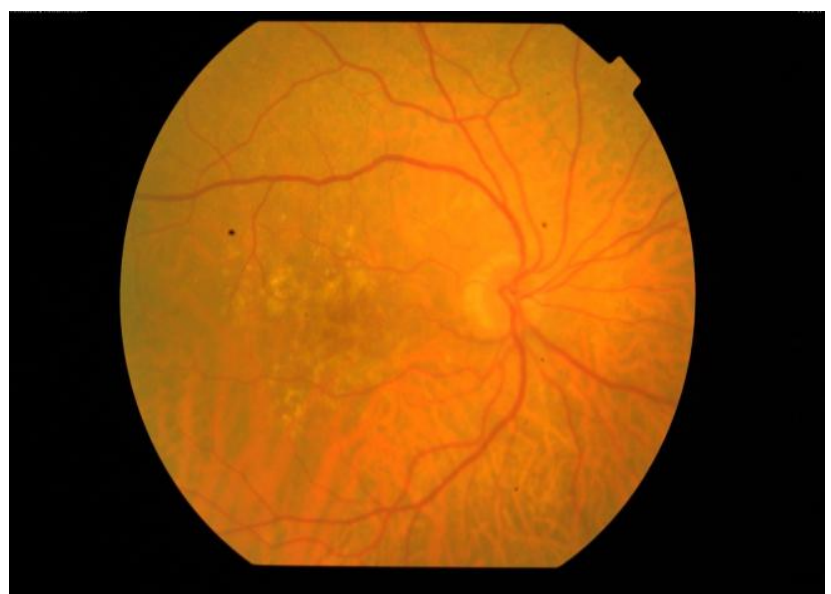

Red free fundus photo showing autofluorescence of drusen

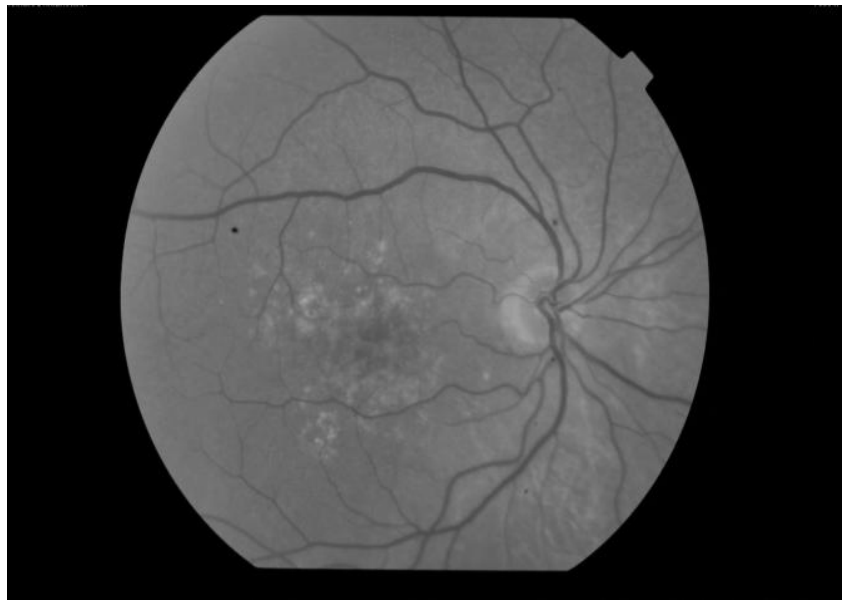

Recording of multifocal ERG

Requires light adaptation for 15 mins

Pupil should be fully dilated

Subject focuses in centre of stimulation monitor

Stimulus used is the array of light\& dark hexagonal flashes.The visual stimulator generates a matrix of 16 to 217 zones which are stimulated with independent sequences of flashes.

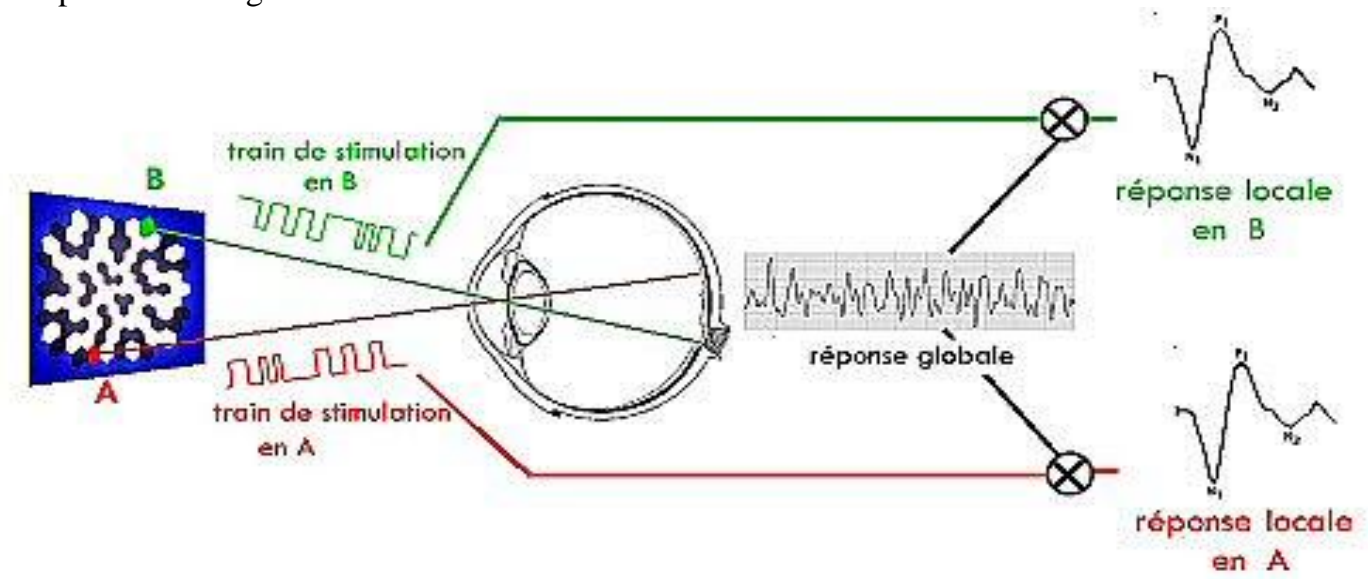

Very high luminance $(400 \mathrm{~cd} / \mathrm{m} 2)$ which allows to obtain high amplitude responses with optimal quality and reduced examination time. Control of the peripheral luminance (surrounding of the stimulation) which eliminates the contamination of ERG responses by rod photoreceptors.
Fixation monitoring with a high resolution video camera.

Visual field covered by the stimulation: up to 30 degrees in eccentricity.

\section{Volume 6 Issue 7, July 2017




\section{International Journal of Science and Research (IJSR) \\ ISSN (Online): 2319-7064}

Index Copernicus Value (2015): 78.96 | Impact Factor (2015): 6.391

Stimulation distance (eye - screen distance): $30 \mathrm{~cm}$.

High frame rate $(120 \mathrm{~Hz})$ allowing a high accuracy for the temporal analysis of responses.

Stimulation frequency $(18 \mathrm{~Hz})$ preserving the morphology of ERG responses by reducing temporal interferences

\section{First-Order Kernel Component of MFERG}

The first-order kernel component of the mfERGis the largest mfERG response derived and thewaveform is a biphasic wave characterized by aninitial negative deflection followed by a positivepeak.. Human firstordermfERG response is dominated by cells of theouter retina such as the photoreceptors and the onand off-bipolar cells.

\section{Second-Order Kernel Component of MFERG}

The waveform of the second-order kernel mfERGis smaller compared with the first-order kernel andis therefore more difficult to measure due to poorersignal-to-noise ratio. It has an initial positive peakfollowed by a negative trough and these are labelled as P1 and N1, respectively. This second orderkernel component was proposed to reflect theinner retinal activity from the retinal ganglion cells.
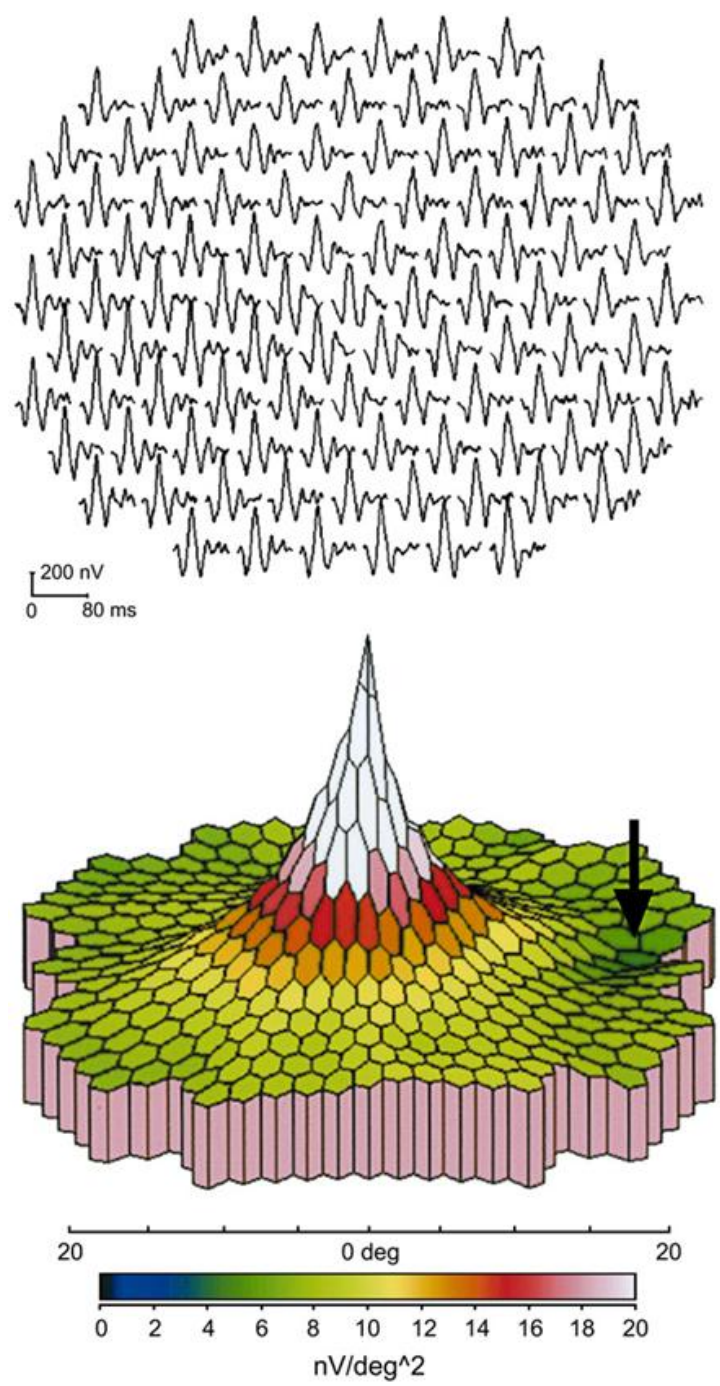

normal multifocal ERG

\section{Result}

The present study is a non randomised prospective study. In our study we found that the change in the amplitude in multifocal ERG following 3 months of antioxidants was not statistically significant in all 5 rings $\&$ on an average of all the 5 rings. We found that $37.5 \%$ patient showed improved visual acuity following 3 months of antioxidant, $40 \%$ patient maintained the visual acuity same as baseline \& in $22.5 \%$ patients visual acuity worsened. In the group of patients with improved visual acuity there was an improvement in amplitude in ring $1 \&$ ring 2 but it was not found to be statistically significant. In the group which maintained visual acuity same as baseline amplitude didn't show significant difference. However in the group of patients with worsened visual acuity there was a statistically significant decrease in the amplitude in ring 1 , ring $2 \&$ on an average suggests that multifocal ERG amplitude changes correlate well with visual acuity changes.

Change in the implicit time in mfERG following 3 months antioxidants compared to baseline mfERG was statistically significant in ring $4 \&$ ring 5 , but overall as an average it is not significant. On comparison of implicit time in patients with improved visual acuity, no significant difference was found. In group of patients with same visual acuity as baseline multifocal ERG demonstrated statistically significant improvement in implicit time after 3 months of antioxidant supplements suggesting that these patients in the long run may possibly demonstrate a visual acuity improvement or at least definite stabilisation. In the group with worsened visual acuity no significant difference was found in implicit time.

Table 1: Comparison of pre-antioxidant and post 3 months of antioxidant values of amplitude at various rings in mfERG among the cases

\begin{tabular}{|c|c|c|c|c|c|}
\hline Variable & & $\begin{array}{c}\text { Mea } \\
\mathbf{n}\end{array}$ & SD & t-value & p-value \\
\hline \multirow{2}{*}{$\begin{array}{c}\text { Ring 1 } \\
\text { Amplitude }\end{array}$} & Pre & 53.89 & $\begin{array}{c}32.7 \\
8\end{array}$ & 1.368 & 0.179 \\
\hline & $\begin{array}{c}\text { Pos } \\
\mathbf{t}\end{array}$ & 47.56 & $\begin{array}{c}19.3 \\
8 \\
\end{array}$ & \multicolumn{2}{|c|}{$\begin{array}{c}\text { Difference is not } \\
\text { significant }\end{array}$} \\
\hline \multirow{2}{*}{$\begin{array}{c}\text { Ring } 2 \\
\text { Amplitude }\end{array}$} & Pre & 31.03 & $\begin{array}{c}14.3 \\
0\end{array}$ & 1.477 & 0.148 \\
\hline & $\begin{array}{c}\text { Pos } \\
\mathbf{t}\end{array}$ & 28.91 & $\begin{array}{c}10.4 \\
9\end{array}$ & \multicolumn{2}{|c|}{$\begin{array}{l}\text { Difference is not } \\
\text { significant }\end{array}$} \\
\hline \multirow{2}{*}{$\begin{array}{c}\text { Ring } 3 \\
\text { Amplitude }\end{array}$} & Pre & 21.58 & 9.07 & 1.460 & 0.152 \\
\hline & $\begin{array}{c}\text { Pos } \\
\mathbf{t}\end{array}$ & 19.66 & 8.21 & \multicolumn{2}{|c|}{$\begin{array}{c}\text { Difference is not } \\
\text { significant }\end{array}$} \\
\hline \multirow{2}{*}{$\begin{array}{c}\text { Ring } 4 \\
\text { Amplitude }\end{array}$} & Pre & 14.76 & 5.40 & 0.789 & 0.435 \\
\hline & $\begin{array}{c}\text { Pos } \\
\mathbf{t}\end{array}$ & 14.12 & 5.53 & \multicolumn{2}{|c|}{$\begin{array}{l}\text { Difference is not } \\
\text { significant }\end{array}$} \\
\hline \multirow{2}{*}{$\begin{array}{c}\text { Ring } 5 \\
\text { Amplitude }\end{array}$} & Pre & 12.78 & 4.48 & 1.040 & 0.305 \\
\hline & $\begin{array}{c}\text { Pos } \\
\mathbf{t}\end{array}$ & 12.12 & 4.86 & \multicolumn{2}{|c|}{$\begin{array}{c}\begin{array}{c}\text { Difference is not } \\
\text { significant }\end{array} \\
\end{array}$} \\
\hline \multirow{2}{*}{$\begin{array}{l}\text { A verage } \\
\text { Amplitude }\end{array}$} & Pre & 26.81 & $\begin{array}{c}11.8 \\
3\end{array}$ & 1.545 & 0.130 \\
\hline & $\begin{array}{c}\text { Pos } \\
\mathbf{t}\end{array}$ & 24.48 & 8.57 & \multicolumn{2}{|c|}{$\begin{array}{c}\text { Difference is not } \\
\text { significant }\end{array}$} \\
\hline
\end{tabular}

$P$ value $>0.05$ 


\section{International Journal of Science and Research (IJSR) \\ ISSN (Online): 2319-7064 \\ Index Copernicus Value (2015): 78.96 | Impact Factor (2015): 6.391}

These values show no significant difference in the pre and post 3 month antioxidant amplitudes in mfERG in all the 5 rings as well as on average.

Table 2: Comparison of pre antioxidant and post 3 months of antioxidant values of implicit time at various rings among

\begin{tabular}{|c|c|c|c|c|c|}
\hline Variable & & Mean & SD & t-value & p-value \\
\hline \multirow{2}{*}{$\begin{array}{c}\text { Ring 1 } \\
\text { Implicit time }\end{array}$} & Pre & 19.94 & 4.02 & 1.55 & 0.129 \\
\hline & Post & 18.78 & 4.80 & \multicolumn{2}{|c|}{ Difference is not significant } \\
\hline \multirow{2}{*}{$\begin{array}{c}\text { Ring } 2 \\
\text { Implicit time }\end{array}$} & Pre & 18.89 & 3.24 & -0.106 & 0.916 \\
\hline & Post & 18.95 & 3.12 & \multicolumn{2}{|c|}{ Difference is not significant } \\
\hline \multirow{2}{*}{$\begin{array}{c}\text { Ring } 3 \\
\text { Implicit time } \\
\end{array}$} & Post & 18.20 & 2.89 & 0.444 & 0.659 \\
\hline & Pre & 18.01 & 3.34 & \multicolumn{2}{|c|}{ Difference is not significant } \\
\hline \multirow{2}{*}{$\begin{array}{c}\text { Ring } 4 \\
\text { Implicit time } \\
\end{array}$} & Post & 18.51 & 2.43 & 2.172 & 0.036 \\
\hline & Pre & 17.71 & 2.79 & \multicolumn{2}{|c|}{ Difference is significant } \\
\hline \multirow{2}{*}{$\begin{array}{c}\text { Ring } 5 \\
\text { Implicit time }\end{array}$} & Pre & 18.58 & 2.62 & 39.000 & 0.048 \\
\hline & Post & 17.80 & 2.96 & \multicolumn{2}{|c|}{ Difference is significant } \\
\hline \multirow{2}{*}{$\begin{array}{c}\text { Average } \\
\text { Implicit time }\end{array}$} & Pre & 18.82 & 2.03 & 1.639 & 0.109 \\
\hline & Post & 18.25 & 2.62 & \multicolumn{2}{|c|}{ Difference is not significant } \\
\hline
\end{tabular}

Implicit time doesn't show statistically significant difference in ring 1 , ring $2 \&$ ring 3 . It shows a significant difference in ring $4 \&$ ring 5 post 3 months antioxidants. But on an average considering all 5 rings the difference in implicit time post 3 months antioxidant treatment is not significant
Table 3: Improvement from pre to post 3 months antioxidant visual acuity among the cases

\begin{tabular}{|l|c|c|}
\hline Visual acuity improvement & No. & Percent \\
\hline Improved & 15 & $37.5 \%$ \\
\hline Same & 16 & $40.0 \%$ \\
\hline Worsen & 9 & $22.5 \%$ \\
\hline Total & 40 & $100.0 \%$ \\
\hline
\end{tabular}

Table 4: Comparison of pre antioxidant and post 3 months antioxidant values of amplitude at various rings among the cases with visual acuity worsened

\begin{tabular}{|c|c|c|c|c|c|}
\hline Variable & & Mean & SD & t-value & p-value \\
\hline Ring 1 & Pre & 76.61 & 26.76 & 5.092 & 0.001 \\
\hline Amplitude & Post & 47.61 & 17.09 & \multicolumn{2}{|c|}{ Difference is significant } \\
\hline Ring 2 & Pre & 40.92 & 13.03 & 2.686 & 0.028 \\
\hline Amplitude & Post & 30.21 & 9.83 & \multicolumn{2}{|c|}{ Difference is significant } \\
\hline Ring 3 & Pre & 24.18 & 9.04 & 1.439 & 0.188 \\
\hline Amplitude & Post & 19.74 & 7.49 & \multicolumn{2}{|c|}{ Difference is not significant } \\
\hline Ring 4 & Pre & 15.90 & 5.87 & 1.360 & 0.211 \\
\hline Amplitude & Post & 13.17 & 5.23 & \multicolumn{2}{|c|}{ Difference is not significant } \\
\hline Ring 5 & Pre & 13.58 & 4.36 & 1.533 & 0.164 \\
\hline Amplitude & Post & 11.67 & 3.87 & \multicolumn{2}{|c|}{ Difference is not significant } \\
\hline A verage & Pre & 34.24 & 11.03 & 3.205 & 0.013 \\
\hline Amplitude & Post & 24.49 & 7.43 & \multicolumn{2}{|c|}{ Difference is significant } \\
\hline
\end{tabular}

This table shows that among the patients with worsening of visual acuity even after the treatment with antioxidant, comparison of amplitude in mfERG pre \& post 3 months antioxidant showed a significant difference in amplitude in ring 1 , ring $2 \&$ on an average.

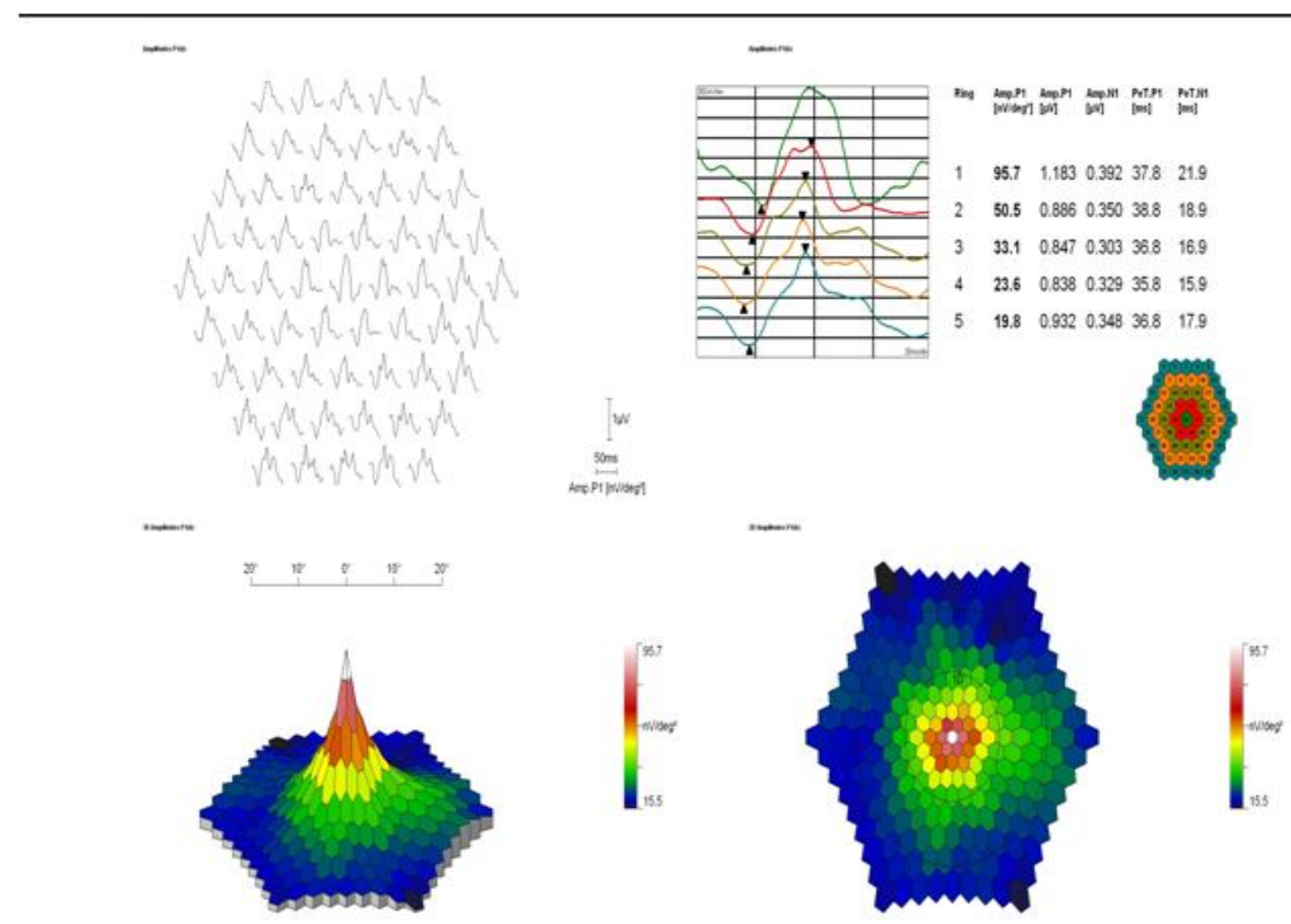

Patient no 1 preantioxidant OD 


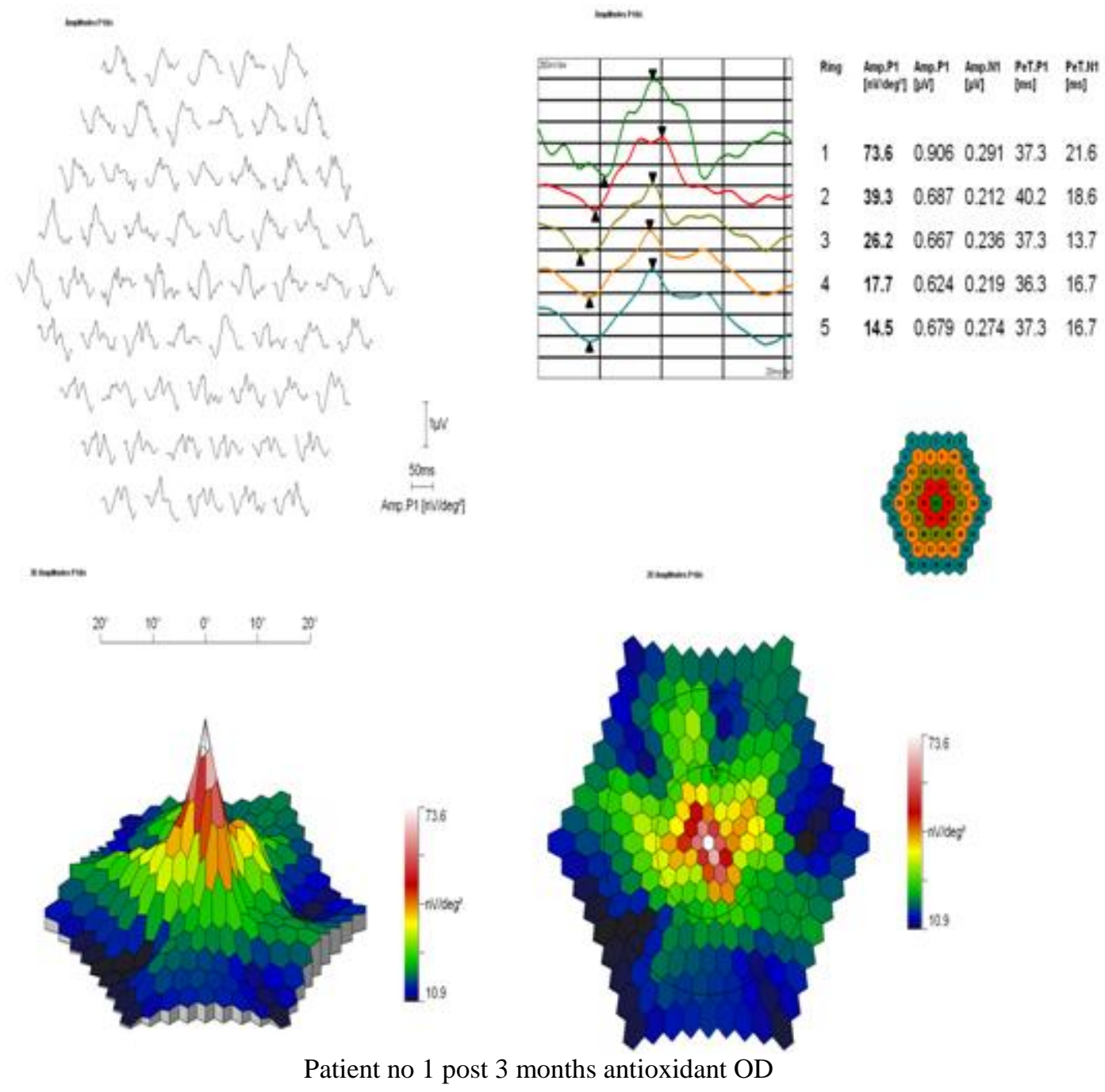

\section{Discussion}

Similar results were obtained in a study by P.J.Penrose, R.Blanco in which they studied 30 patients with intermediate \& advanced AMD, divided them into 2 groups, one group received lutein supplementation \& other group received placebo. It was a randomised, prospective control study. In this study they could not detect any improvement in functional parameters as measured by $\mathrm{mfERG}^{16}$.

In contrast in Las Vegas study ${ }^{17}$ results showed that the electroretinogram recordings from patients in the supplementation group showed a statistically significant improvement from baseline to the 3-month follow-up but remained unchanged in the control group.

Alsoa pilot study sponsored by Macular Health, LLC, evaluated patients with dry age-related macular degeneration (DAMD) and found that all patients improved in visual acuity and retinal function with the use of the Macular Health supplement formula. In this study mfERG was used at baseline and after a two-month follow-up of ten patients' eyes without nutritional supplements compared to ten patients' eyes placed on daily high-dose beta carotene, vitamin $\mathrm{C}$, vitamin $\mathrm{E}$, zinc, copper, lutein, and zeaxanthin.The supplementation group improved in amplitude density in the $\mathrm{N} 1 \quad(\mathrm{P}=.002)$ and $\mathrm{P} 1 \quad(\mathrm{P}=.005)$ waves in all six rings. (EDTRS) Visual Acuity improved for the nutritional supplement group ${ }^{18}$.

Strength of our study lies in the fact that it is a prospective study. However our study has a smaller study group and short follow up of only 3 months. So we don't know what happens in long run. Whether after continuing antioxidants for a longer duration we will be able to show significant improvement on mfERG or not remains unanswered. Also we are not able to comment whether stopping antioxidants will worsen the mfERG or not. All these require a study with larger no of subjects with a long term follow up to comment whether mfERG can be useful or not firmly.

\section{Conclusion \& Summary}

In this study we tried to explore the role of mfERG in the management of the patients with dry AMD. We observed that there was no significant improvement in the amplitude in mfERG above the baseline post 3 months antioxidant treatment on an average in all the patients. In the group of patients with worsened visual acuity there was a statistically significant decrease in the amplitude in ring 1 , ring $2 \&$ on an average suggests that multifocal ERG amplitude changes correlate well with visual acuity changes

Also we observed in our study that mfERG failed to show any significant improvement in implicit time on an average.

\section{Volume 6 Issue 7, July 2017} www.ijsr.net 


\section{International Journal of Science and Research (IJSR) \\ ISSN (Online): 2319-7064 \\ Index Copernicus Value (2015): 78.96 | Impact Factor (2015): 6.391}

However in ring 4 \& ring 5 independently implicit time showed significant reduction in all patients. It was seen in our study that group of patients where visual acuity stabilised there was a significant improvement in implicit time thus suggesting that longer use of antioxidants was essential to demonstrate any appreciable improvement in visual function.

Multifocal ERG is definitely useful investigative tool to access improvement or deterioration of visual function vis-àvis visual acuity. And the changes in multifocal ERG correlate well with the changes in the visual function in patients with dry AMD.

\section{References}

[1] Clemons TE, Milton RC, Klein R, Seddon JM, Ferris FL III. Risk factors for the incidence of advanced agerelated macular degeneration in the Age-Related Eye Disease Study (AREDS): AREDS report no. 19. Ophthalmology 2005; 112:533-539.

[2] Jampol LM, Ferris FL 3rd. Antioxidants and zinc to prevent progression of age-related macular degeneration. JAMA 2001;286:2466-8.

[3] Seddon JM, Hennekens CH. Vitamins, minerals, and macular degeneration: promising but unproven hypotheses. Arch Ophthalmol 1994;112:176-9.

[4] Anzai K, Mori K, Ota M, et al: [Aging of macular function as seen in multifocal electroretinograms]. Nippon Ganka Gakkai Zasshi 102:49--53, 1998

[5] Fortune B, Johnson CA: Decline of photopic multifocal electroretinogram responses with age is due primarily to preretinal optical factors. J Opt Soc Am A Opt Image Sci Vis 19:173--84, 2002

[6] Gerth C, Garcia SM, Ma L, et al: Multifocal electroretinogram: age-related changes for different luminance levels. Graefes Arch Clin Exp Ophthalmol 240:202--8, 2002

[7] Gerth C, Sutter EE, Werner JS: mfERG response dynamicsof the aging retina. Invest Ophthalmol Vis Sci 44:4443--50,2003

[8] Jackson GR, Ortega J, Girkin C, et al: Aging-related changes in the multifocal electroretinogram. J Opt Soc Am A Opt Image Sci Vis 19:185--9, 2002

[9] Mohidin N, Yap MK, Jacobs RJ: Influence of age on the multifocal electroretinography. Ophthalmic Physiol Opt 19:481--8, 1999

[10] Nabeshima $T$, et al: The effects of aging on the multifocal electroretinogram. Jpn Ophthalmol 45:114--5, 2001

[11] Nabeshima T, Tazawa Y, Mita M, et al: Effects of aging on the first and second-order kernels of multifocal electroretinogram. Jpn J Ophthalmol 46:261--9, 2002

[12] Seiple W, Vajaranant TS, Szlyk JP, et al: Multifocal electroretinography as a function of age: the importance of normative values for older adults. Invest Ophthalmol Vis Sci 44:1783--92, 2003

[13] Tam WK, Chan H, Brown B, et al: Aging and mfERG topography. Eye 20:18--24, 2006

[14] Tzekov RT, Gerth C, Werner JS: Senescence of human multifocal electroretinogram components: a localized approach. Graefes Arch Clin Exp Ophthalmol 242:549-60, 2004
[15] Age-Related Eye Disease Study Research Group. A randomized, placebo-controlled, clinical trial of highdose supplementation with vitamins $\mathrm{C}$ and $\mathrm{E}$, beta carotene, and zinc for age-related macular degeneration and vision loss: AREDS report no. 8. Arch Ophthalmol 2001;119:1417-1436.

[16]P.J. Penrose ${ }^{1}$, R. Blanco ${ }^{2}$, D. Rajguru ${ }^{1}$, M. Wang ${ }^{2}$, J. Lee $^{1}$, W. Fung ${ }^{1}$ and E.E. Sutter ${ }^{2}$ Invest Ophthalmol Vis Sci 2004;45: E-Abstract 3123.@ 2004

[17] Multifocal Electroretinogram Study of Patients Placed on SupplementalVitamins ,Minerals, and Carotenoids for Dry Macular Degeneration. Abstract PO716

[18] News From The Annual Meeting Of The American Academy Of Ophthalmology,2006 Macular Health, LLC

\section{Abbreviations}

AMD : Age related macular degeneration mfERG : multifocal electroretinogram AREDS : age related eye disease study 